\title{
Demandas Psicológicas de Pacientes Pediátricos em Quimioterapia Sequencial
}

\author{
Azevedo, Priscilla Caroliny Reis de; Lage, Ana Maria Vieira; Maia, Anice Holanda Nunes; \\ Damasceno, Brenna Paula; Shioga, Júlia Evangelista Mota; Lima, Maria Juliana Vieira
}

Universidade Federal do Ceará - priscilla_caroliny@hotmail.com

Introdução: a Quimioterapia é o recurso mais utilizado no combate ao câncer infanto-juvenil. no entanto, se configura como um processo ambivalente, pois ao mesmo tempo em que possibilita a cura, por outro lado representa sofrimento, haja vista seus efeitos colaterais. Estudos a respeito dessa fase demonstram que a rotina do tratamento quimioterápico altera rapidamente a vida cotidiana dos pacientes e de seus acompanhantes, trazendo consigo fatores ansiogênicos, como: internação intermitente, afastamento dos amigos e da escola, procedimentos invasivos, restrição alimentar, alopécia, dentre outros. Aspectos que podem gerar sérias consequências psicológicas envolvendo fantasias em torno da terapêutica, da doença e de si mesmo, que podem ocasionar prejuízos ao tratamento ou o abandono do mesmo. Objetivos: Caracterizar as demandas psicológicas que surgem em pacientes durante as sessões de quimioterapia seqüencial em um centro de tratamento do câncer infanto-juvenil. Metodologia: Foi realizado um estudo exploratório transversal descritivo, com abordagem qualitativa, a partir dos registros de intervenção psicológica, no setor supracitado, durante nove meses situados entre o período de maio 2012 a abril 2013. Empregou-se estatística descritiva para os dados quantitativos do perfil sócio-assistencial e análise de conteúdo temática para os dados qualitativos dos registros das intervenções. Resultados: Foram realizados 230 atendimentos e verificou-se que $58,4 \%$ dos pacientes são do sexo masculino entre 11 e 18 anos (35,1\%) e 66,1\% são procedentes do interior do estado. no que se refere à demanda dos pacientes, constatou-se que $82 \%$ consistiram em estabelecer contato e/ou realizar atividades lúdicas e apenas $18 \%$ representaram demanda por atendimento psicológico. Além disso, foi averiguado que $80,3 \%$ das intervenções se configuraram como acolhimento e $19,7 \%$ como alguma das seguintes intervenções: psicoterapia de apoio, psicoeducação, interconsulta e intervenção lúdica. Conclusões: a unidade de Quimioterapia Sequencial caracteriza-se como um ambiente estressor, consequentemente, os pacientes sentem-se mais ansiosos devido aos fatores citados acima e, principalmente à ociosidade. Essa situação pode justificar a predominância da demanda por estabelecimento de contato e/ou intervenção lúdica, constatada no estudo. Os resultados suscitam discussão a respeito de uma postura mais humanizada e menos patologizante dos profissionais que convivem com esses pacientes, uma vez que, diferente do que pode-se imaginar diante do ambiente aversivo da unidade referida, os pacientes apresentaram, em sua maioria, estabilidade emocional, justificando a predominância do acolhimento sobre os outros tipos de intervenção, uma vez que através do acolhimento pode-se mediar estratégias de enfrentamento e adaptação do paciente ao câncer e a essa fase do tratamento, além de fortalecer o vínculo entre o paciente e o profissional do serviço, o que pode ampliar a rede de apoio do sujeito.

Azevedo, Priscilla Caroliny Reis de; Lage, Ana Maria Vieira; Maia, Anice Holanda Nunes; Damasceno, Brenna Paula; Shioga, Júlia Evangelista Mota; Lima, Maria Juliana Vieira. Demandas Psicológicas de Pacientes Pediátricos em Quimioterapia Sequencial.. In: Anais do Congresso Internacional de Humanidades \& Humanização em Saúde [= Blucher Medical Proceedings, num.2, vol.1]. São Paulo: Editora Blucher, 2014. ISSN 2357-7282

DOI 10.5151/medpro-cihhs-10778 